\title{
Upwelling in the Kerch Strait and the Adjacent Waters of the Black Sea Based on the Contact and Satellite Data
}

\section{P. D. Lomakin}

Marine Hydrophysical Institute, Russian Academy of Sciences, Sevastopol, Russian Federation e-mail: p_lomakin@mail.ru

Local and large-scale upwellings in the Kerch Strait and in the Black Sea adjacent waters are considered based on the contact and satellite data. The spatial scales and the temporal variability characteristics of these phenomena as well as regularities of thermohaline field transformation are identified. It is shown that a stable northwestern wind generates local upwelling pockets in the southern and central areas of the Kerch Strait. Quite a rare natural phenomenon when a wind-generated local upwelling induces temperature rise in the coastal waters is described. The upwelling observed in late September is accompanied by water temperature growth in the strait. It is revealed that the Black Sea subsurface waters that flow to the strait within the upwelling circulation system and that are of total suspended and dissolved organic matters low concentrations, contribute to improving water quality. Large-scale upwelling is originated in the Feodosiya Gulf; its influence extends to the Kerch Strait and to a wide strip along the eastern coast of the Crimea. The cycle of this kind of upwelling varies within the range of 1-8 days. Maximum frequency is typical for an upwelling cycle of about 24 hours. Considerably variable on interannual scale temporal characteristics of a large-scale upwelling off the eastern coast of the Crimea and in the Kerch Strait are shown on the quantitative level.

Keywords: upwelling, temperature, salinity, total suspended matter, dissolved organic matter, the Kerch Strait.

Acknowledgements. The work was fulfilled within the framework of the State Orders No. 08272014-0011 Research of the Regularities of Changes In the Condition of the Marine Environment on the Basis of Operational Observations and Data of the System Of Diagnosis, Prognosis and Reanalysis of the Condition of Marine Areas (Operational Oceanography code) and No. 0827-2014-0010 Complex Interdisciplinary Research of the Oceanological Processes Determine the Functioning and Evolution of the Ecosystems of the Black and Azov Seas, based on Modern Methods for Marine Environment State and Grid Technologies (Fundamental Oceanology code).

For citation: Lomakin, P.D., 2018. Upwelling in the Kerch Strait and the Adjacent Waters of the Black Sea Based on the Contact and Satellite Data. Physical Oceanography, [e-journal] 25(2), pp. 114-123. doi:10.22449/1573-160X-2018-2-114-123

DOI: $10.22449 / 1573-160 X-2018-2-114-123$

(C) 2018, P. D. Lomakin

(C) 2018, Physical Oceanography

Introduction. The most significant mechanism, that realizes the water exchange between the shelf and the deep-water part of the oceans and seas is associated with upwelling. This phenomenon, observed in all climatic zones of the World Ocean and in the seas, is of great practical importance and is intensively studied by marine scientists of different countries [1-4].

Wind-generated upwelling is a typical phenomenon for the Black Sea and for the Crimean coast particularly. Therefore, it has been relatively well studied. Many publications of the Soviet and modern Russian oceanologists [5-9], based on experimental contact and satellite data, as well as on results of numerical modeling [10, 11], are devoted to this phenomenon. The main result of these studies can be formulated in the way below.

Along with upwelling generated by local winds, there is its larger scale view in the Black Sea, which has not been sufficiently studied. One of the possible mechanisms of this phenomenon is associated with the aquatic environment response to 
atmospheric circulation. It is believed that large-scale upwelling is mainly due to the effect of the large-scale atmospheric processes over the Azov and Black Seas, while the role of local winds and coastal current systems is less significant. This type of upwelling is common throughout the Black Sea perimeter, except its eastern coast. Its sources have a spatial scale of tens (up to hundreds) miles, where in the vertical circulation system the intermediate and deep waters with their own properties enter the upper layer, substantially changing the structure of hydrophysical, hydrochemical and hydrobiological elements' fields [8].

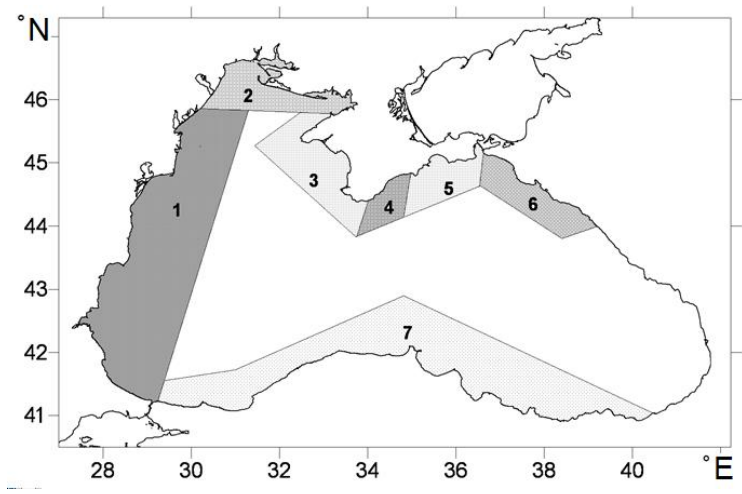

Fig. 1. The Black Sea zoning scheme of the large-scale coastal upwelling intensity [8]. Studied area Area 5

The present work gives the analysis of the aforementioned types of the upwelling and their manifestation in the thermohaline field in the Kerch Strait waters and the adjacent water area near the eastern coast of Crimea (Fig. 1), a region where similar studies have not been carried out before, based on satellite and contact information. For the first time, the structure of the fields of the aquatic environment parameters, non-traditional for classical oceanography, - the concentration of the total suspended (TSM) and dissolved organic matter (DOM) in the local upwelling region, is considered.

Initial data and methods of research. The cases of local wind-generated upwelling directly in the Kerch Strait are analyzed on the basis of data from two joint complex expeditions of the staff of Marine Hydrophysical Institute (MHI) and the South Scientific Research Institute of Marine Fisheries and Oceanography (YugNIRO) in August and September 2011.

Statistical data on the temperature field structure on the sea surface and spatial characteristics of large-scale upwelling are calculated based on the YugNIRO satellite data array [8]. Temporal variability of this upwelling type is obtained on the basis of the satellite image array analysis in the infrared range for 2000-2015 taken from the MHI archive [12]. The search for large-scale upwelling zones was carried out from May to September, when they are most clearly manifested in the temperature field on the sea surface. For each detected case of this upwelling, the formation and decay time of the corresponding temperature inhomogeneity were recorded. The cycle time was determined in hours and then averaged to a day. For each spe- 
cific year, the number of days, when upwelling was observed near the eastern coast of Crimea, was calculated

The total number of images analyzed was 2211 , and in 279 of them, the signs of large-scale upwelling were traced.

Discussion of the results. Local wind-generated upwelling in the Kerch Strait. 2 to 3 days earlier and during the two expeditions, a stable weak northwestern wind was observed over the Kerch Strait. It was due to the rear part of the cyclone with the center in the Caspian lowland region. The first survey was carried out in August 1-2 under the western northwestern wind with a speed of 2-6 m/s; the second one - in September 26-28 under northern northwestern wind with a speed of 3$5 \mathrm{~m} / \mathrm{s}$. In both situations, the vector of the wind flow tangential stress had a predominant surge component directed to the southeast.

In [13] for the northwestern Black Sea and the Crimean coast, typical wind roses generating local upwelling at the certain parts of the marine area are shown. According to this work, in the Kerch Strait and the adjacent Black Sea waters this type of upwelling is due to the northwestern wind. Its annual repeatability is $18 \%$ (according to results in [14]). That is, the situations considered in the present study correspond to the specific wind conditions that cause the surge phenomena in the considered water area.

Analysis of the thermohaline field structure based on the materials of both expeditions, made it possible to detect signs of coastal upwelling associated with the wind surge. In particular, it was revealed that in the upwelling system caused by the offshore wind, the subsurface Black Sea waters came to the Kerch Strait to meet the wind flow from the southern pre-strait area. In August, the upwelling was accompanied by the water temperature decrease, whereas in September the wind surge caused an opposite effect - warming of practically the entire coastal water column.

See the more detailed consideration of these phenomena below.
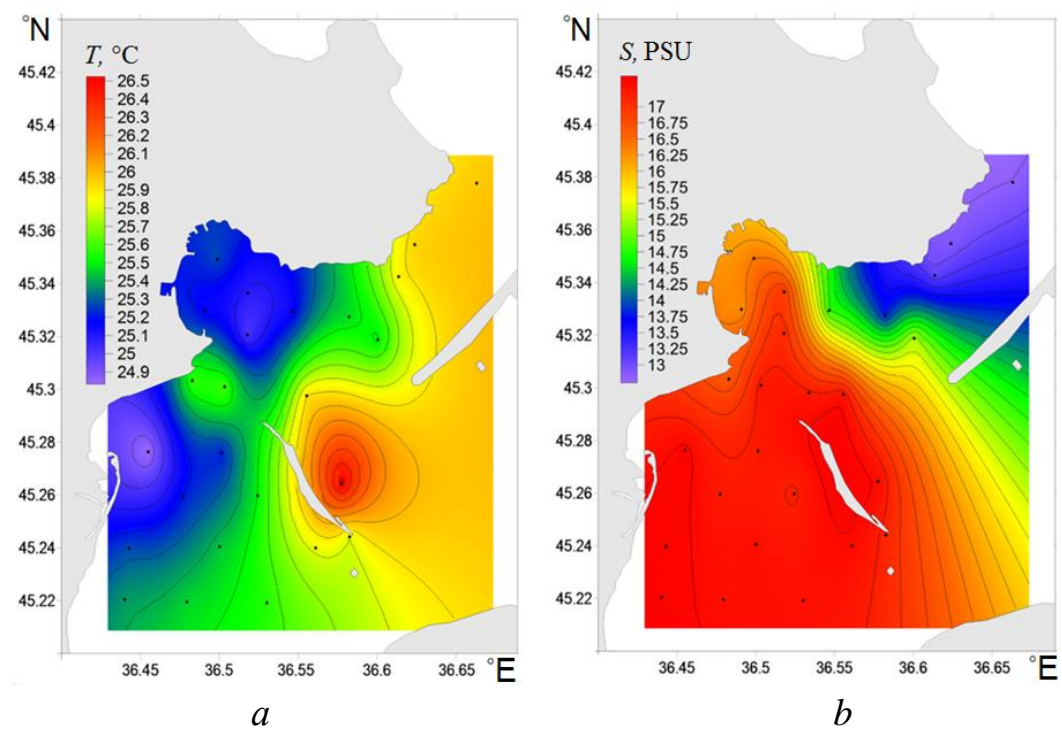

Fig. 2. Temperature $(a)$ and salinity $(b)$ distribution in the upper layer of the Kerch Strait area in August 1-2, 2011 
On the August survey materials, the surge source area near the Kerch coast of the Strait is clearly visible in the structure of the temperature field (Fig. 2,a). This is most marked in the Kerch and Kamysh-Burun bays, in the Pavlovskaya Narrowness and adjacent shallow areas. The minimum temperature fixed here is 24.40 $25.21 \mathrm{C}$, which is $2-3^{\circ} \mathrm{C}$ below the background values.

The salinity field analysis (Fig. 2,b) shows that in the upwelling system caused by the offshore wind, highly saline waters from the bottom layer of the Black Sea pre-strait area entered the strait. Their salinity reached 17.64 18.53 PSU, which is 1.6-2.5 PSU higher than the background values.

The upwelling source area from the seaward side was limited by the frontal section is well shown in the thermohaline field (Fig. 2).

According to instrumental measurement data, near the bottom at the most stations in the southern part of the strait the vectors of current having velocity of 5 $25 \mathrm{~cm} / \mathrm{s}$ were directed to the Kerch coast. It is confirmed by the local surge mechanism caused by the western northwestern wind.

The influence of warm $\left(25.82-26.60^{\circ} \mathrm{C}\right)$ and low salinity (12.68-13.67 PSU) Azov Sea waters extended to the northern parts of the strait (Fig. 2).

The September survey, whose range covered the vast water area of the Kerch Strait to its southern border, seems most informative (Fig. 3, 4). In this situation, the wind surge was also accompanied by the waters' exit from the subsurface structural zone of the Black Sea to the Kerch Strait. The peculiarity of the case analyzed is that the strait waters by the end of September turned out to be fairly cooled to a temperature lower than in the Black Sea waters, the rise of which in the upwelling system was accompanied by the temperature growth. The changes in the salinity field at the quantitative level in August and September were similar.
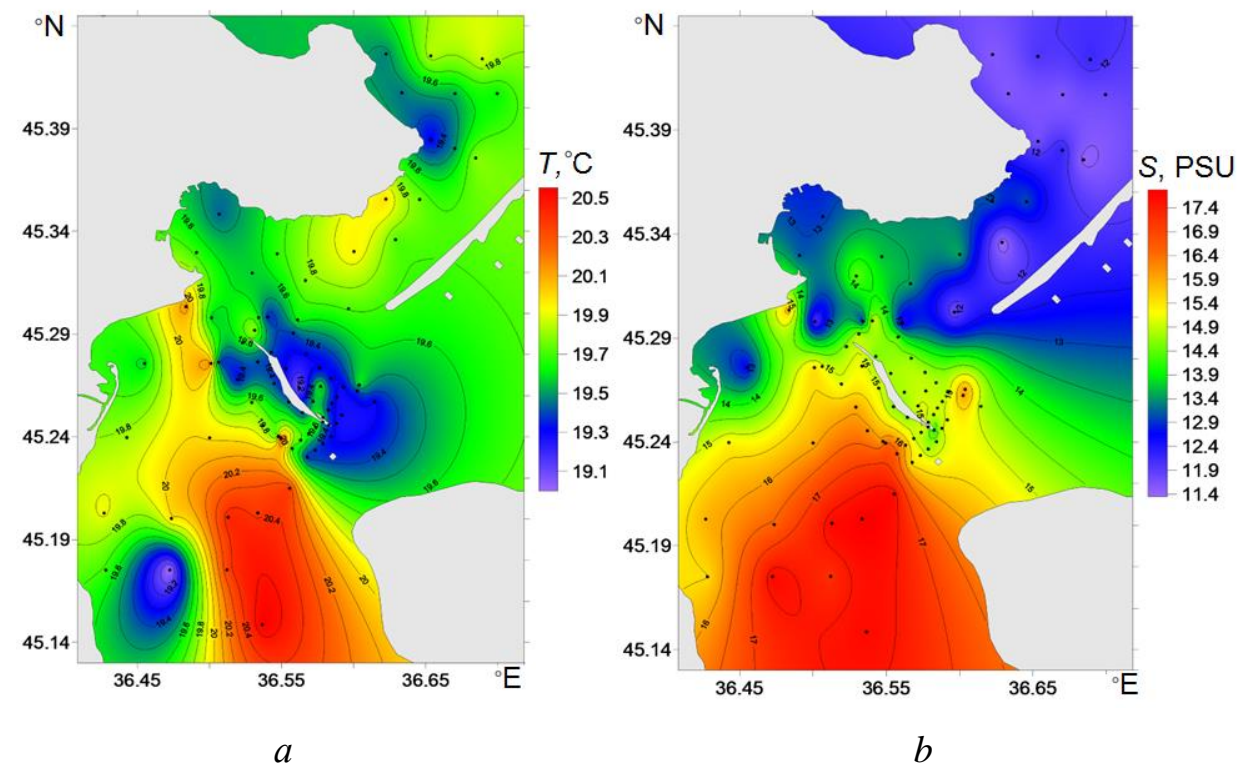

Fig. 3. Temperature $(a)$ and salinity $(b)$ distribution in the upper layer of the Kerch Strait area in September 26-28, 2011 

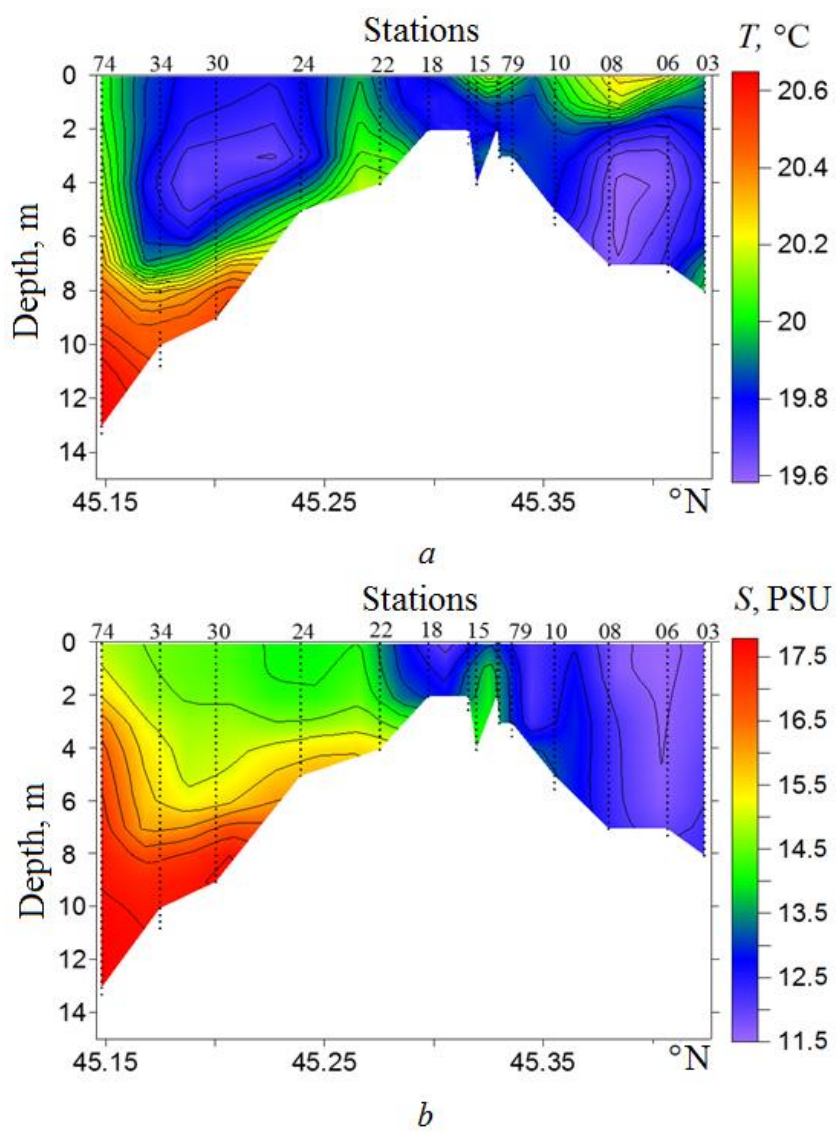

Fig. 4. Temperature $(a)$ and salinity $(b)$ distribution on the longitudinal section through the Kerch Strait in September 26-28, 2011

The flow of warm and salty Black Sea waters that entered into the strait is clearly visible in the schemes of horizontal distribution of temperature and salinity on the surface, and especially in the bottom layer. Its northern, eastern and western peripheries were represented by the thermohaline frontal section, located to the north of the Tuzla Island, appeared in the entire water column (Fig. 3).

In the surge source, the maximum water temperature at the surface and at the bottom reached 19.90 and $20.55^{\circ} \mathrm{C}$, respectively, which is 0.46 and $1.61^{\circ} \mathrm{C}$ higher the surrounding background. The similar ratios for salinity are 15.75 and 17.90 PSU; 1.46 and 2.50 PSU.

The ascent of the warm and saline subsurface Black Sea waters along the southern underwater slope of the Kerch Strait and their distribution in the compensatory current system further to the north, to the central area of the strait, are shown in Fig. 4. The warmest $\left(20.35-20.65^{\circ} \mathrm{C}\right)$ and saline (16.20-17.72 PSU) layer of 2$5 \mathrm{~m}$ thick was observed at the bottom.

As a result, an inversive vertical stratification of the temperature field was formed in the sections of the southern underwater slope of the strait. Steady stratification in the density field was provided by a positive vertical salinity gradient. 
The absolute increment of temperature and salinity with depth reached $0.53-$ $1.03^{\circ} \mathrm{C}$ and $2.02-2.54 \mathrm{PSU}$ (Fig. 4).

The situation described above illustrates a rare natural phenomenon (rather, rarely fixed instrumentally), when the wind surge is accompanied by the coastal water column warming up.

A qualitatively different effect (the decrease - increase in the water temperature) caused by the same mechanism of wind surge is explained by the different temperature background of the waters of the considered water area during the surveys analyzed.

In both situations, the saline Black Sea waters came out in the shallow Kerch Strait waters. In August, when the strait is maximum warm, these waters had a lower temperature. At the end of September, at the beginning of the period of autumn heat delivery, the background values of the water temperature in the strait turned out to be lower than the temperature of the Black Sea water penetrating its shallow water area in the upwelling circulation system.

Analysis of additional data showed that local wind-generated upwelling not only deforms the thermohaline field structure of the strait's water in a special way, it also has a corresponding response in the TSM and DOM content fields.

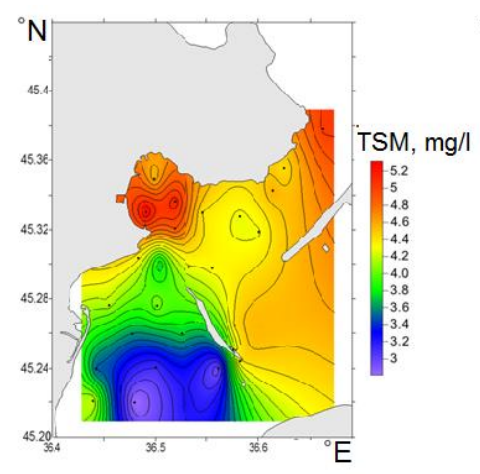

$a$

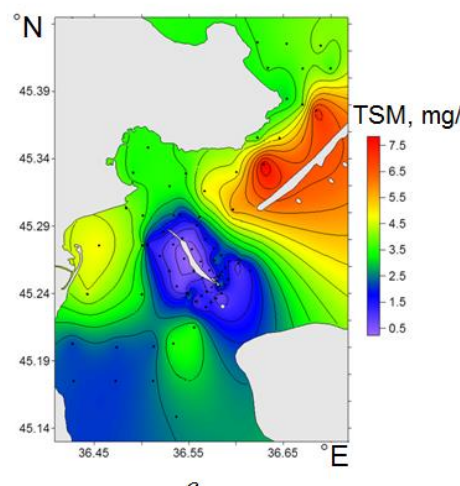

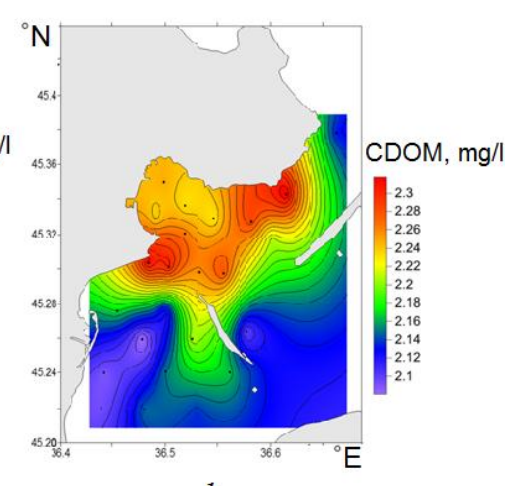

$b$

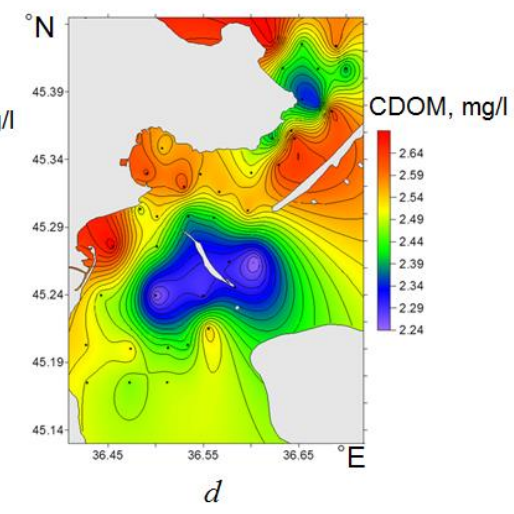

Fig. 5. Total suspended $(a)$ and dissolved organic $(b)$ matter distribution on the surface in the Kerch Strait in August 1-2, 2011. The same characteristics $(c, d)$ in September 26-28, 2011

In the upwelling circulation system in the Kerch Strait, which waters (as a consequence of the permanent anthropogenic press) are characterized by high TSM 
and DOM concentrations, subsurface Black Sea waters with a low (natural) content of these substances enter. In Fig. 5 it can be seen that, according to materials of the expeditions analyzed, these waters were occupied by the southern and central water areas of the Kerch Strait. The content of TSM and DOM here was significantly lower than in the northern part of the considered water area, which indicates the importance of wind upwelling as a factor improving the quality of waters in the Kerch Strait.

Note that DOM is considered the most effective indicator of contaminated water [15]. Due to the complexity of determining the content of this substance, mass information about it became possible relatively recently. This parameter has been lately actively used to assess the quality of waters in coastal ocean and marine areas $[15,16]$.

For the analysis of large-scale upwelling in the considered area, the attention should be turned to the scheme of Black Sea water area zoning according to the typical signs of upwelling of this type proposed in [8] (see Fig. 1). According to the work quoted, the Kerch Strait refers to one of the seven regions of the Black Sea coastal water area - the area near the eastern coast of Crimea (including the Kerch Strait, Feodosiya Gulf and Karadag Reserve) with typical hydrophysical signs of large-scale upwelling.

Large-scale upwelling in the Black Sea is characterized by the following features. Within the region of this upwelling type formation at its early stage, a spatial heterogeneity is usually observed in the water temperature field on the sea surface, which eventually transforms into separate cold water centers, called upwelling "centers". In the considered water area most often such formations are located near the Feodosiya Gulf coast.

At the later stages of coastal cold water source development, cold jets (sometimes called upwelling "rays") propagate toward the open sea and along the coastline, the peripheries of which have pronounced frontal traits. On the considered section of the Crimean coast, the extent of frontal formations oriented mainly to the south reaches $\sim 70$ miles. As a result, intermediate and subsurface waters with low temperature values and a high concentration of nutrients are carried away to the considerable distances from the shore. The upper layer in the system of ascending circulation can also get water from the hydrogen sulphide zone of the Black Sea.

Manifestation of the upwelling "rays" in the water temperature field along the shores of the Crimean Peninsula is illustrated on a satellite IR image (Fig. 6) [12]. These structural features of large-scale upwelling are clearly visible near the eastern shore of Crimea, along its southern coast and in its west (near the Tarkhankut Cape).

The average width of the coastal zone near the eastern shore of Crimea, covered by large-scale upwelling, is 39 miles.

In July-August, the surface water temperature in the the water upwelling source area (the Feodosiya Gulf) decreases to $6-7^{\circ} \mathrm{C}$ relative to the surrounding background. In the Kerch Strait, located on the eastern periphery of the water area under the large-scale upwelling effect, the water temperature drops by $2-3^{\circ} \mathrm{C}$. The centers of this upwelling type in the studied water area are most often formed in July. 


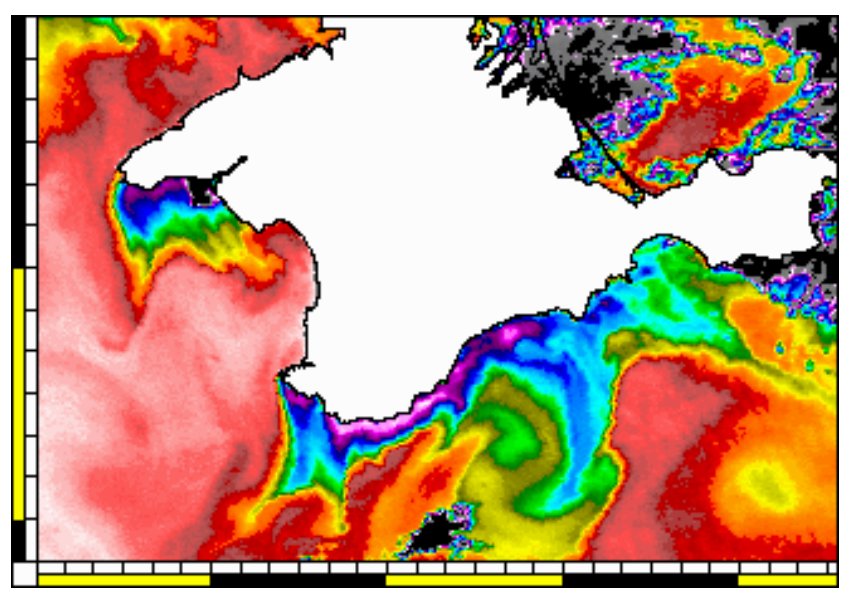

Fig. 6. "Rays" of the large-scale upwelling (dark blue color) near the Crimea shores on the satellite IR image dated July 3, 2003 (11:00 GMT)

Analysis of the upwelling cycle duration showed the following. For the 2000 2015 period on satellite images near the eastern coast of Crimea, 132 cases of upwelling with a cycle duration of 1-8 days were recorded. The upwelling with a cycle of 7 days were not monitored. Below the data on the repeatability of largescale upwelling with different cycle times is shown:

$\begin{array}{lrrrrrrrr}\text { Cycle (days) } & 1 & 2 & 3 & 4 & 5 & 6 & 7 & 8 \\ \text { Repeatability (\%) } & 45 & 23 & 17 & 8 & 5 & 1 & 0 & 1\end{array}$

With the $45 \%$ repeatability, the short period upwelling with a cycle time of about a day was most often noted. The upwelling with a cycle exceeding 5 days were extremely rare. Their total repeatability is $2 \%$.

Analysis of the number of days with signs of upwelling for each specific year indicates a significant interannual variability in the frequency of the studied phenomenon formation near the eastern coast of Crimea. Thus, in the 2000-2015 three gaps with a noticeable difference in the corresponding indicator are distinctly distinguished. These are: in 2000-2003, annual average (warm period of the year) duration of time with upwelling was 17 days with an absolute range of variability of 11-20 days; in 2004-2010, upwelling was observed much less frequently and these indicators decreased to a minimum of 5 days with an absolute range of variability of 2-8 days; in 2011-2015, the cases of upwelling were noticeably more frequent, on average for a year the time duration when it was observed and the absolute interval of variability increased to 51 days and to 48-57 days, respectively.

Conclusion. Patterns of the transformation of the fields of a number of oceanological elements in local and large-scale upwelling sources in the Kerch Strait and adjacent water areas near the eastern coast of Crimea are considered based on the analysis of the data of the two expeditions and satellite information.

It was revealed that in August and September 2011 a weak steady northwestern wind caused the formation of upwelling source in the south and in the central 
part of the strait. The upper layer was compensated by the flow of subsurface waters from the Black Sea pre-strait area, which, having risen along the southern underwater slope of the strait, reached its center. In August, upwelling was accompanied by the water temperature decrease by $2-3^{\circ} \mathrm{C}$. In September, the Black Sea waters that emerged on the cooled shallow parts of the strait contributed to the temperature growth by $0.5-1.6^{\circ} \mathrm{C}$, as well as to the formation of an inversion stratification of the temperature field. In the both situations salinity increased by $1.5-$ 2.5 PSU.

It is shown that the Black Sea waters coming in the local wind upwelling system and possessing a natural concentration of TSM and CDOM contribute to the Kerch Strait water quality improvement.

In the studied area, along with upwelling generated by a local drift wind, there is a large-scale upwelling, the formation of which is associated with large-scale atmospheric processes over the Black Sea. In the Kerch Strait and near the eastern coast of Crimea, it can be manifested in the absence of pronounced local wind factors.

The large-scale upwelling in the considered water area most often originates in the Feodosiya Gulf. The temperature at the surface in its sources relative to the background values decreases by $6-7^{\circ} \mathrm{C}$ in the Feodosiya Gulf and by $2-3 \mathrm{C}$ in the Kerch Strait. Average width of the alongshore zone, where the upwelling effect is traced, is 39 miles, and the maximum length of its "rays" oriented to the south reaches 70 miles. This type of upwelling in the considered water area is most often observed in July. The duration of its cycle varies in the interval 1-8 days. The maximum repeatability (45\%) is typical for upwelling with a cycle duration of about a day. The upwelling with a cycle exceeding 5 days are extremely rare.

It has been quantitatively shown that the time characteristics of large-scale upwelling at the eastern coast of Crimea and in the Kerch Strait vary significantly on an interannual scale.

\section{REFERENCES}

1. Bakun, A., 1990. Global Climate Change and Intensification of Coastal Ocean Upwelling. Science, [e-journal] 247(4939), pp. 198-201. doi:10.1126/science.247.4939.198

2. Sarhan, T., Lafuente, J.G., Vargas, M., Vargas, J.M. and Plaza, F., 2000. Upwelling Mechanisms in the Northwestern Alboran Sea. J. Mar. Syst., [e-journal] 23(4), pp. 317-331 doi:10.1016/s0924-7963(99)00068-8

3. Mann, K.H. and Lazier, J.R.N., 2006. Dynamics of Marine Ecosystems: Biological-Physical Interactions in the Oceans. Malden, USA: Blackwell Publishing, 503 p. doi:10.1002/9781118687901

4. Blanchette, C.A., Wieters, E.A., Broitman, B.R., Kinlan, B.P. and Schiel, D.R., 2009. Trophic Structure and Diversity in Rocky Intertidal Upwelling Ecosystems: A Comparison of Community Patterns across California, Chile, South Africa and New Zealand. Progr. Oceanogr., [e-journal] 83(1-4), pp. 107-116. doi:10.1016/j.pocean.2009.07.038

5. Bogdanova, A.K. and Kropachev, L.N., 1959. Sgonno-Nagonnaya Cirkulyaciya i Eyo Rol' v Gidrologicheskom Rezhime Chernogo Morya [Surge Circulation and Its Role in the Hydrological Regime of the Black Sea]. Meteorologiya i Gidrologiya, (4), pp. 26-33 (in Russian).

6. Blatov, A.S. and Ivanov, V.A., 1992. Hydrology and Hydrodynamics of the Shelf Zone of the Black Sea (on the example of the Southern Coast of the Crimea). Kiev: Naukova Dumka, 244 p. (in Russian). 
7. Ginzburg, A.I., Kostianoy, A.G., Soloviev, D.M. and Stanichny, S.V., 1997. Pribrezhnyj Apvelling v Severo-zapadnoj Chasti Chernogo Morya [Coastal Upwelling in the North-West Black Sea]. Issledovanie Zemli iz Kosmosa, (6), pp. 61-72 (in Russian).

8. Borovskaya, R.V., Lomakin, P.D., Panov, B.N. and Spiridonova, E.O., 2008. Struktura i Mezhgodovaya Izmenchivost' Harakteristik Pribrezhnogo Chernomorskogo Apvellinga na Osnove Dannyh Sputnikovogo Monitoringa [Structure and Interannual Variability of Characteristics of Inshore Black Sea Upwelling on Basis of Satellite Monitoring Data]. Issledovanie Zemli iz Kosmosa, (2), pp. 26-36 (in Russian).

9. Csanady, G.T., 1977. Intermittent 'Full' Upwelling in Lake Ontario. J. Geophys. Res., [e-journal] 82(3), pp.397-419. doi:10.1029/JC082i003p00397

10. Kosnyrev, V.N., Mikhailova, E.N. and Stanichny, S.V., 1997. Upwelling in the Black Sea by the Results of Numerical Experiments and Satellite Data. Physical Oceanography, [e-journal] 8(5), pp. 329-340. doi:10.1007/BF02523759

11. Sur, H.İ., Özsoy, E. and Ünlüata, Ü., 1994. Boundary Current Instabilities, Upwelling, Shelf Mixing and Eutrophication Processes in the Black Sea. Progr. Oceanogr., [e-journal] 33(4), pp. 249-302. doi:10.1016/0079-6611(94)90020-5

12. MHI, 2017. The Satellite Data Archive on the Black Sea. [online] Available at: http://dvs.net.ru/mp/data/main_ru.shtml [Accessed 19 October 2017].

13. Apvelling $v$ Chernom more [Upwelling in the Black Sea]. [online] Available at: http://meteopost.com/info/Upwelling/ [Accessed 19 October 2017].

14. Lomakin, P.D., Panov, D.B. and Spiridonova, E.O., 2010. Specific Features of the Interannual and Seasonal Variations of Hydrometeorological Conditions in the Region of Kerch Strait for the Last Two Decades. Physical Oceanography, 20(2), pp. 109-121. https://doi.org/10.1007/s11110-010-9071-5

15. Boss, E., Pegau, W.S., Zaneveld, J.R.V. and Barnard, A.H., 2001. Spatial and Temporal Variability of Absorption by Dissolved Material at a Continental Shelf. J. Geophys. Res., [e-journal] 106 (C5), pp. 9499-9507. https://doi.org/10.1029/2000JC900008

16. Tedetti, M., Longhitano, R., Garcia, N., Guigue, C., Ferretto, N. and Goutx, M., 2012. Fluorescence Properties of Dissolved Organic Matter in Coastal Mediterranean Waters Influenced by a Municipal Sewage Effluent (Bay of Marseilles, France). Environ. Chem., [e-journal] 9(5), pp. 438-449. doi:10.1071/EN12081

About the author:

Pavel D. Lomakin - Senior Research Associate, Oceanography Department, FSBSI MHI (2, Kapitanskaya Str., Sevastopol, 299011, Russian Federation), Ph.D. (Geogr.), Professor, ResearcherID: V-7761-2017, p_lomakin@ mail.ru

The author has read and approved the final manuscript.

The author declares that he has no conflict of interest. 